\title{
SPATIAL METAPHORS OF TIME IN ROMAN CULTURE
}

\begin{abstract}
As cognitive structures that capture patterns of sensorimotor experience, image schemas and their metaphorical interpretations not only deliver meaning in Latin's semantic system, but also organize other forms of Roman symbolic representation. This paper builds on Maurizio Bettini's analysis of Latin's metaphorical expression of time in terms of linear spatial relations by tracing the structuring effects of these metaphors on other aspects of Roman social practice, including its artistic practice. As I argue, apart from their linguistic manifestations, these metaphors motivate the "axial" configurations of certain socially instituted genealogical representations, as well as provide principles of organization for the construction and decoration of material objects.
\end{abstract}


As a broadly interpretive discipline that seeks to shed light on the meanings elaborated by members of Greek and Roman society in linguistic and other forms of representation, classical studies has long been interested in the relationship between words (or, more narrowly, texts) and images. This interest has developed in part as a result of disciplinary history: classical archaeology and art history first grew as branches of philology and often have been marked by a strongly textual orientation. ${ }^{1}$ It also arises in part because, as Jás Elsner reminds us, the ancients themselves did not always neatly distinguish words from images: ${ }^{2}$ in Greek, for instance, the root of $\gamma \rho \alpha \varphi \eta$,

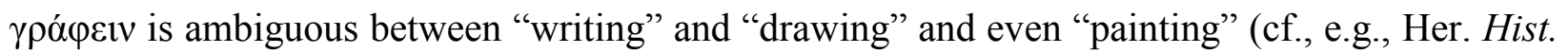

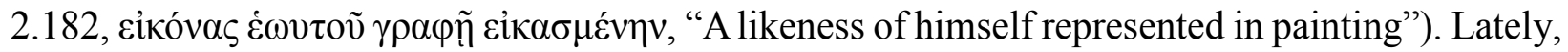
special attention has been paid to the ways in which words and images appear to express analogous meanings: ${ }^{3}$ A certain scenic description in a literary text—say, that of the maenads in Euripides' Bacchae (680-713) or of the temple of Apollo at Delphi in Ion (184-236) — can be said to be "like a picture" in evoking highly vivid images or even a specific work of art. ${ }^{4}$ Or a certain configuration of elements in a visual image can be said to capture meanings akin to a certain literary trope or even a specific figure of speech. ${ }^{5}$ Very often, the visual has actually been understood in "linguistic" terms: Claude Bérard in fact took the structure of language as an explicit model for analyzing Greek art in terms of syntactic combinations and paradigmatic substitutions. ${ }^{6}$ Similarly, Tonio Hölscher suggested that Roman art be treated as a "semantic system" (semantisches System) conveyed through a "language of images" (Bildsprache). ${ }^{7}$

Given this strong disciplinary interest in the relationship between word and image, the study of metaphor suggests itself as a fruitful area of research. Recent developments in the so-called "second generation" cognitive sciences show it to be a particularly promising subject, as it has been suggested that metaphor may function as a key node where linguistic and visual signification 
intersect. A central claim of theories of "embodied" cognition and language is that much of people's ability to make sense of and communicate about their experience is delivered by conceptual structures that emerge from the interaction of brain, body, and environment. In cognitive linguistics, the meanings of many words are taken to correspond-either directly or indirectly through figurative interpretation - to recurring patterns of sensorimotor experience or "image schemas." However, because image schemas are taken to operate at a very general level of understanding — and so may motivate symbolic representations of many different kinds - in my view their study affords the possibility of bringing together linguistic semantics with the interpretation of works of art (not to mention other forms of imaginative expression) under a unified cultural semiotics. ${ }^{8}$ To illustrate what this might look like, in this paper I re-analyze and extend Maurizio Bettini's findings on Latin's expression of time in terms of metaphors of horizontal and vertical linear relations by tracing the structuring effects of these metaphors on other aspects of Roman society's symbolic activity, including its artistic practice. Apart from their linguistic manifestations, these metaphors, I propose, not only motivate the specific axial configurations of certain socially instituted genealogical representations, but also provide principles of topographical organization for the construction and decoration of material objects, as well as the mechanism of their interpretation.

\section{LATIN'S SPATIAL METAPHORS OF TIME.}

Theories of embodiment developed in the cognitive sciences posit that human meaning makingwhether in language or any other form of symbolic representation-depends crucially on the character of human bodily engagement with the world. ${ }^{9}$ Traditional (formal) philosophical and linguistic semantics defines concepts in terms of "necessary and sufficient" features represented 
in the mind as language-like symbols and governed by syntactic principles. Proponents of the embodied view of meaning argue, instead, that categorization is grounded in humanly determined perceptual, interactional, functional, and purposive properties. ${ }^{10}$ Thus, many categories are "adhoc" or "goal-derived" categories constructed on the basis of prior experience or context-induced value judgments ("things one takes on a camping trip," "things to save from a burning house"), ${ }^{11}$ or out of richly imagined concrete scenes: even a seemingly highly stable taxonomy such as fruit, for instance, is probably not understood as something like "any sweet and fleshy product of a plant that contains seeds and can be eaten," but constructed on the fly by scanning memories of the produce section of a grocery store. ${ }^{12}$ Or consider the category of what is fake. Fake negates certain functional properties of the concepts it modifies, while preserving others: for instance, a fake gun looks like a real gun (perceptual), can be handled like one (interactional), and can be used in some of the same situations as one (purposive); however, it cannot perform the primary functions of a gun (killing) and was not designed to do so.

In many cases, scholars now claim that the meanings of words are actually defined imagistically or, to use the term of art, "image-schematically" — an image schema being, as Mark Johnson writes, "a recurring dynamic pattern of our perceptual interactions and motor programs that gives coherence and structure to our experience." ${ }^{\prime 13}$ In this theory, image schemas are highly abstract structures of cognition that are correlates of (because dependent on the same neural architecture as) sensory and motor experience, and are thus susceptible of visual and kinesthetic transformation "in the mind's eye"-rotation, scanning, clustering or segmentation, superimposition, path or end-point focus, following a trajectory, reflexivity and so forth —as well as combination into more complex scenarios. ${ }^{14}$ Cognitive linguists argue that image schemas may also be metaphorically interpreted as a support to abstract conceptualization, projecting conceptual 
structure and content from more readily comprehensible concrete domains to those less grounded in physical experience. ${ }^{16}$ In this way, image schemas are said to provide the inferential patterns that motivate the range of senses typically characterizing the meanings of words. ${ }^{17}$

Consider the preposition $d \bar{e}$. As I have argued, its meaning cannot be "out of" or "away from" (let alone "down from") expressed in such propositional format. ${ }^{18}$ In the idiom $d \bar{e}$ tergo and expressions like aram . . de qua pariens arbore nixa dea est (Ov. Her. 21.99-100), its sense actually seems to include motion toward a location (the back, the tree). In etiam si cecidit de genu pugnat (Sen. Dial. 1.2.6) the preposition must be interpreted in the sense not simply of "from," but more specifically of "up from." Even if we take $d \bar{e}$ 's meaning to be some very general notion of separation, its sense in deligare and devincire ("bind (together)"), where it implies the narrowing of physical space between two things, show this to be inadequate. To explain de्es full range of senses, we must instead take its meaning to be an image schema that portrays two bounded regions and a trajector's motion between these regions. In this way, conventional uses of $d \bar{e}$ in which the preposition designates the source point of something as it moves closer to the position of the implied observer, or where the motion is seen as being in a direction away from the observer, can be accounted for in terms of naturalistic shifts of perspective over the imagined scenario. Moreover, dē's abstract senses—its ability to denote, e.g., topicality ("about, concerning"), genealogical and kinship relations, negation, strengthening, pejoration — can then be explained on the basis of regularly occurring metaphors in Latin's semantic system, whereby the regions are interpreted as IDEAS, STATES, and so on.

Latin speakers' conceptualization of time exemplifies just this sort of image-schematic structuring. If in somewhat different terms, Maurizio Bettini has argued that Latin's conventional ways of talking about time are in fact organized by two metaphors in which temporal relations are 
conceived through images of one-dimensional linear spatial relations. ${ }^{19}$ In one metaphor, time is imagined as a vertically oriented line and temporal relations are understood in terms of schematic images of "above" and "below." Thus, as examples (1) to (9) illustrate, Latin speakers say that one time (a night, a day, a year ... ) or event (a battle, a crime, a marriage ... ) is "above (supra)" or "higher than (superior)" another to mean that it happened before: ${ }^{20}$

(1) quid superiore nocte egeris, "What you did on the previous night" (Cic. Cat. 1.1);

(2) nonne timuisse ... non parietes denique ipsos superiorum testis nuptiarum? "Did she not fear . . . the very walls, finally, as witnesses of her previous marriage?" (Clu. $6.15)$

(3) non oblivione amicitiae ... superioribus temporibus ad te nullas litteras misi, "I have not neglected to send you any letters in the past days out of any forgetfulness of our friendship" (Fam. 5.17.1);

(4) milites superioribus proeliis exercitati, "Soldiers trained in previous battles" (Caes. BG. 2.20);

(5) has superioribus diebus refecerat atque omnibus rebus instruxerat, "He had completely refitted and rigged these (sc. ships) in the preceding days" (BC. 2.5);

(6) testimonium conveniens superiori facto, "Evidence fitting the previous act" (Hirt. BG. 8.53);

(7) paulo supra hanc memoriam, "A little before the memory of this generation" (Caes. BG. 6.19.5);

(8) res est praeterea et immensi operis, ut quae supra septingentesimum annum repetatur, "My subject involves great labor, to trace back more than seven hundred years" (Liv. AUC. 1.pr.4); 
(9) praetoribus de superioris anni actis referentibus, "The praetors made a motion respecting the transactions of the prior year" (Suet. Iul. 23). ${ }^{21}$

Conversely, Latin speakers say that a time is "below (infra)" or "lower than (inferior)" another to mean it happened after: e.g.,

(10) cum intercalatur inferiores quinque dies duodecimo demuntur mense, "When it (sc.

February) is intercalated, the last five days are removed from the twelfth month" (Var. LL. 6.13);

(11) non infra superiorem Lycurgum fuit, "He (sc. Homer) was not after the elder Lycurgus" (Cic. Brut. 40);

(12) aetate inferiores paulo quam Iulius, "A little younger in age than Julius" (182);

(13) erant inferiores quam illorum aetas, "They were younger than those men" (Q.Fr. $3.5 .2) ; 22$

(14) Ciceronis temporibus paulumque infra, "In Cicero's days and a little later" (Quint. IO. 1.7.20);

(15) transiit ad inferiora tempora . . cum sentiret neque libere neque vere sibi de superioribus tradendi potestatem relictam, "He (sc. Claudius) skipped over to later times ... since he felt that no opening had been left for him to deal freely and truly with the previous events" (Suet. Claud. 41.2).

In other words, Latin's conventional ways of expressing temporal relations are structured systematically by a set of conceptual correspondences according to which 'BEFORE IS ABOVE' and 'AFTER IS BELOW. ${ }^{23}$ These correspondences can be represented as a series of mappings or correspondences between the domain of spatial relations and that of time — namely, "a vertical line $\rightarrow$ time's progress," "above, up (on the line) $\rightarrow$ earlier time, before," and "below, down (on the 
line) $\rightarrow$ later time, after." They can also be represented graphically as in Figure 1, where the solid line represents the vertical axis in three-dimensional coordinate geometry and coordinates "above" and "below" represent earlier and later times, respectively. $<$ FIGURE 1: ABOVE/BELOW schema underlying Latin's expressions of temporal relations.>

In the other metaphor, the time line is imagined as oriented horizontally (as a line extending through the body from back to front) and temporal relations are understood in terms of "before" and "behind" - in other words, in terms of their relative position "in front of" or "in back of." There are two possibilities. As examples (16) to (22) illustrate, time may be conceived as a subject's movement forward towards the future, times being static points along the trajectory of motion towards or to which the subject "goes" or "arrives" or "approaches":

(16) adolevit ad eam aetatem, "She has grown up to that age" (Plaut. Cas. 47-48);

(17) semper ego usque ad hanc aetatem ... tuis servivi servitutem imperiis, "Even up to this present age, I have always ... paid all submission to the injunctions" (Trin. 301);

(18) etsi pervivo usque ad summam aetatem, "Even if I live to the greatest old age" (Plaut. Capt. 742);

(19) pervenisse te ad ultimum aetatis humanae videmus, "We see that you have come through to the last moment of a man's life" (Sen. Brev. vit. 3.2);

(20) non cunctabitur sapiens ire ad mortem certo gradu, "The wise man will not hesitate to meet death with a sure step" (11.2);

(21) cogita brevitatem huius spatii, per quod citatissimi currimus, "Consider the shortness of this space, through which we run so very fast" (Ep. mor. 99.7);

(22) qui proxime praetextati aetatem accedet, "who will soon approach the age of young adulthood" (Iust. Dig. 43.30.3.6). 
In this subject-moving image, the subject's position corresponds to "now" and a time's being "in front of" the subject means it is in the future and its being "in back of" the subject means it has already occurred in the past. This can be represented graphically by Figure 2, where the solid line represents time as the horizontal axis in a three-dimensional coordinate space and the arrow represents motion along this axis (and thus, metaphorically, temporal progression). $<$ FIGURE 2: FRONT/BACK schema in subject-moving expressions. $>$ It is important to recognize here that PAST and FUTURE on the time line are defined relative to ego's bodily orientation. That is, according to the conceptual correspondences set up by the mappings of this metaphor, 'THE PAST IS BEHIND' and 'THE FUTURE IS IN FRONT (OF EGO)'. ${ }^{24}$ This is why (usque) ad-literally, "(all the way) to(ward)" — has the figurative meaning it does: though ad can indicate motion conceivably in any direction (as, e.g., in Ov. Fast. 6.786, ad stellas aliquis talia verba iacit, it includes the notion of motion upward through contextual modulation), in human embodied experience, movement tends to occur in the direction we are facing. In metaphorically projecting spatial dimensionality onto the conception of time, ego therefore moves forward along the time line in the direction of $(a d)$ specific time-points in the future. This is why in (23) to (26), the adverb porro has the temporal meaning "in the future": what is literally "straight on, forward, onward" relative to ego on the time line is metaphorically yet to occur: e.g.,

quid mi hic adfers quam ob rem exspectem aut sperem porro non fore? "What are you offering me, why I should expect or hope it will not happen in the future?" (Ter. Phorm. 1025); me sollicitum ... esse atque porro fore, "That I was disturbed and would be for the future" (Cat. Orat. fr. 39); 
(25) ni te perdite amo atque amare porro / omnes sum assidue paratus annos, "Unless I love you madly and am ready to love you in the future without stopping through all the years" (Catull. Carm. 45.3-4);

(26) neque quemquam alium diuinare posse, quid in animo Celtiberi haberent aut porro habituri essent, "Nor could anyone else guess what the Celtiberi intended, or what they were going to intend in the future" (Liv. AUC. 40.36.2).

This is also why one "looks backward" (respicere) to past events in Latin, as demonstrated by, e.g.,

(27) cum respicias inmensi temporis omne / praeteritum spatium, "When you look back at the whole passed-by space of immeasurable time" (Luc. RN. 3.854-55);

(28) nam quoad longissime potest mens mea respicere spatium praeteriti temporis, "For as far as my mind can look back at the space of bygone time" (Cic. Arch. 1); (29) nec enim illis uacat praeterita respicere, "Nor do they have leisure to look back at what has gone before" (Sen. Brev. vit. 10.2);

(30) nemo ... libenter se in praeteritum retorquet, "No one gladly ... twists himself back toward the past" (10.3);

(31) cras vel atra / nube polum pater occupato / vel sole puro; non tamen inritum / quodcumque retro est efficiet neque / diffinget infectumque reddet / quod fugiens semel hora vexit. "Let Jupiter tomorrow with black / clouds preempt the sky / or bright sun: yet he will not cross out / whatever is behind or redivise / and make undone what once / the fleeting hour has brought" (Hor. Carm. 3.29.43-48);

(32) iam post terga reliquit sexaginta annos, "Behind his back, he has left sixty years" (Juv. Sat. 13.16), ${ }^{25}$

and why, equally, one "looks forward" (providere or prospicere) to future events: 
(33) si quae eventura sunt provideant, "For if anything is to come out, let them foresee" (Pac. Trag. fr. 407);

(34) quod ego . . sensi atque providi, "which I . . perceived and foresaw" (Cic.

Vat. 2.4);

(35) in hoc enim fallimur, quod mortem prospicimus, "For in this we are deceived, that we look ahead to death" (Sen. Ep. mor. 1.2.3).

Alternatively, times can be seen as moving together from the future toward past from the perspective of a subject who occupies a fixed position on the time line. Thus, as examples (36) through (43) show, times are said to "come (venire)," "draw near (appropinquare)," "approach (accedere, appetere)," "come up (incidere)" and even "flow," "fall away," or "slip by" a person:

(36) iam appetit meridies, "Already midday approaches" (Plaut. Most. 636);

(37) quasi vero tempus dandi muneris non valde appropinquaret, "As if in reality the time for the exhibition was not drawing very near" (Cic. Sul. 54);

(38) non numquam eius modi tempora incidunt, "Sometimes occasions like this come upon us" (Fin. 1.32);

(39) quo plus sibi aetatis accederet, "The more old age approaches on him" (De orat. 254);

(40) veniet ... aetas, "The age will come" (Verg. Aen. 1.283);

(41) multa ferunt anni venientes commoda secum, "The years coming bring many advantages with them" (Hor. Ars 175);

(42) lenior et melior fis accedente senecta? "Do you become softer and better when old age approaches?” (Hor. Ep. 2.2.211); 

with silent years" (Ov. Fast. 6.771).

In this time-moving image, events are reified, assigned a definite front and back (very likely through a projection of the human "body set": cf. Todes 2001), and oriented according to the time line's directionality. This can be represented as in Figure 3, where the solid line again represents time as the horizontal axis, and the circles labeled $x, y$, and $z$ represent distinct times whose movement with the time line constitutes temporal progression. $<$ FIGURE 3: FRONT/BACK schema in time-moving expressions.> Consequently, according to the conceptual mappings of this metaphor, one time's or event's being "in front of (ante)" another means it happened before and its being "behind (post)" means it happened after (as in the Figure time $x$ is in front of and therefore earlier than time $y$, and time $z$ is behind and therefore later than time $y$, from ego's point of view)irrespective of whether these temporal relations belong to a future or a past time (i.e., ego's position does not necessarily correspond to "now"). That is, metaphorically speaking, 'BEFORE IS IN FRONT' and 'AFTER IS BEHIND', as exemplified by:

(44) ante lucem a portu me praemisisti domum, "Before daybreak, you sent me from the harbor home before you" (Plaut. Am. 602);

(45) ante solem occasum, "Before sunset" (Epid. 144);

(46) ante vesperum, "Before evening" (Bacch. 1029);

(47) ante brumam, "Before winter" (Ter. Phorm. 709);

(48) ante hanc urbem conditam, "Before the founding of this city" (Cic. TD. 5.3.7);

and by:

(49) qui foret post illa natus, "Who was born after these things" (Enn. Trag. fr. 67 Vahlens); 
(50) post id cum lassus fueris, "After that, when you're tired out" (Plaut. Cas. 130);

(51) eum ... numquam post illa vidi, "I never saw him after that" (Curc. 529);

(52) aliquot post menses, "After some months" (Cic. Rosc. Am. 128);

(53) post M. Brutum proconsulem, "After the proconsulate of M. Brutus" (Phil. 2.38.97);

(54) Socrates Critoni dixit sibi post tertium diem esse moriendum, "Socrates said to Crito that after three days' time he would have to die" (Div. 1.52). ${ }^{26}$

\section{LATIN'S SPATIAL METAPHORS AS A “FOLK” MODEL OF TIME.}

Evidence indicates that alongside these LINEAR metaphors a number of other metaphors contributed to Latin speakers' understanding of time. For instance, figurative usage of the verb impendere with aevum ("age, era"), vita ("life"), biennium ("two-year period"), and other words denoting temporal intervals implies Latin speakers could sometimes conceive of time as something to "weigh out" and thus (because in Roman society payments were originally made with weighed metals) "spend" as money. Perhaps Seneca (Brev. vit. 11.2) elaborates this image most fully when he describes the time of one's life as something that cannot be "transferred as a debt" (delegatur) or "lessened by prodigality" (largitione detrahitur), but that is to be viewed instead "entirely as income" (tota ... in reditu est). Similarly, when Ovid speaks of "voracious time" (Met. 15.234, edax tempus) and again of "voracious oldness" (Met. 15.872, edax vetustas), or Seneca writes that "greedy time devours us" (Troad. 400, tempus nos avidum devorat), this implies Latin speakers could also conceive of time in terms of (animalistic?) eating. Expressions like Vergil's volvendis mensibus (Aen. 1.269), Lucretius' volventia lustra (RN. 5.928), and Ovid's volvens annus (Met. 5.565) indicate they could conceptualize time in cyclic terms as well. In this light, the overall 
system of metaphors converging on Latin speakers' conceptualization of time probably resembles something like Figure 4.<FIGURE 4: Metaphors converging on Latin speakers' conceptualization of time.>

Why does this range of different images converge on Latin speakers' metaphorical conceptualization of time? Cognitive linguists argue that where a concept is defined by several distinct metaphors, these metaphors typically work together to produce a coherent understanding of that concept's various aspects. ${ }^{27}$ While the metaphors may fail to provide a consistent image to conceptualization, nevertheless they tend to fit together as a system, each metaphor delivering an understanding of some dimension of the metaphorically defined concept not covered, or only partially covered, by the others. Just so, the "weighing out" metaphor maps Latin speakers' knowledge about the function of money onto time, so that time can be assigned a value and treated like any other resource or market commodity. ${ }^{28}$ The "devouring" metaphor maps knowledge about how hungry animals eat their prey onto the time, to help convey something about its destructive effects: namely, that it acts quickly, ferociously, and without mercy on human beings. The "revolving" metaphor maps what is most likely an astronomical image of the apparent revolution of the sun, moon, and stars in the sky onto time, to capture the perception that time is ordered by continuously repeated temporal units (days, months, seasons, years). ${ }^{29}$ The vertical and horizontal metaphors, meanwhile, project paired spatial images onto time as a means of imposing a basic scalar structure on the otherwise undifferentiated flow of time.

Still, the sorts of meanings delivered by Latin's MONEY, CYCLE, and EATING metaphors of time need to be distinguished from those of the LINEAR metaphors. To begin with, these metaphors involve the projection of conceptual content that tends to be relatively rich in structure and imagistically complex: correspondingly, the meanings they make available to Latin speakers are 
highly particular and so contextually circumscribed. Furthermore, they are largely "one-shot" metaphors that map isolated images onto the conceptualization of (specific aspects of) time and consequently lack widespread effects in Latin's semantic system. For instance, while it is possible to find a word like orbis ("circle") referring to the repetitive nature of temporal events, ${ }^{30}$ it does not seem to be idiomatic to speak in Latin of, say, time's "circumference" or of an "arc" of time: the image of "revolving" times may in fact be dependent on a Greek poetic metaphor. ${ }^{31}$ Similarly, we do not find Latin speakers conventionally referring to temporal events as "coins," nor to time's "jaws" or "fangs." At the same time, the images of "weighing out" time and of time that "devours" are specialized subcases of metaphors that operate at a high order of semantic structure: the former characterizes a very general concept of devoting a large amount of some (literal or figurative) resource to an activity, while the latter defines the destructive effects of any (again literal or figurative) force.

The LINEAR metaphors, by contrast, deliver images to Latin speakers' conceptualization of time that are structurally and imagistically minimal: that is, ABOVE, BELOW, FRONT and BACK all represent structures of meaning that depict highly schematic spatial configurations consisting of a limited number of elements largely undefined as to their conceptual content. They also involve pairings of images that are systematically related, in the sense that ABOVE and BELOW, FRONT and BACK are contrastive images whose opposition in understanding emerges naturally from human bodily experience. ${ }^{32}$ Because of gravity's pervasive operation on our bodies and objects within terrestrial environments, we experience things as being "up" or "down" in relation to one another. Likewise, because the sensorimotor capacities through which we engage with our environments tend to be localized on one side of the human body, we understand ourselves as functionally asymmetrical also on the horizontal axis: we understand ourselves, that is, as having a definite 
"front" and "back." Accordingly, in being interpreted metaphorically of time, these images characterize a very general understanding of this domain - in effect delineating time as an aspect of experience and endowing temporality with a relational structure - and so organize a great portion of Latin speakers' talk about time over different authors and genres, different periods of the language, and different levels of the linguistic code.

This is not to suggest that the horizontal and vertical images of time are in any way fungible in Latin. ${ }^{33}$ While serving the same basic function, their meaning differs in at least one important respect. Through the metaphorical mapping of images of ABOVE/BELOW spatial relations onto the conceptualization of time, temporal relations in this image emerge as a difference of values inherent in the time scale itself. The vertical metaphor thus focuses on a subject-neutral or "allocentric" view of temporal relations. Through the mapping of FRONT/BACK orientation onto times, temporal relations in this image are instead construed always relative to a specific perspective (even if no commitment is made as to the location of a subject's now) — the horizontal metaphor thus focusing on a more subject-oriented or "egocentric" view. In this way, Latin's LINEAR metaphors of time appear to work together to capture the very likely universal human experience of time both as something that exists independently of and prior to any individual subjectivity (that is, we understand that time is not defined by any one human existence) and as something inextricably bound up with that subjectivity (still, we experience time as ordered fundamentally by our own human concerns and indeed as something we can personally "have"). ${ }^{34}$ Though these images, which are inconsistent in that one construes time along a vertical and the other along a horizontal axis, probably would not suffice for rigorous scientific theorizing, as a system they nevertheless constitute a workable "folk" model apparently sufficient to Latin speakers' reasoning and communicating about temporal relations for most everyday purposes. ${ }^{35}$ 


\section{AND AS A “CULTURAL" MODEL.}

Of course, Latin is not unique in recruiting spatial imagery — and indeed images of horizontal and vertical spatial relations very particularly - towards the metaphorical conceptualization of time. Cognitive linguists have described this as a feature of many-and, what's more, many typologically unrelated-languages, even if the relative incidence of each image varies from language to language. ${ }^{36}$ In English and German, for example, the horizontal metaphor is robustly evidenced and the vertical metaphor is extremely attenuated, ${ }^{37}$ while French preserves the latter in expressions like haut moyen âge ("early," literally "high middle age") and basse antiquité ("late," literally "low antiquity"). ${ }^{38}$ Similar situations obtain in Hindi, Sesotho, Turkish, Hawaiian, many South American languages, Japanese, and Mandarin Chinese-where it is possible to find the spatial terms shàng ("up") and xià (“down") as well as qián ("front”) and hòu ("back”) used in

time expressions to signify "last" and "next," respectively. ${ }^{39}$ Linear spatialization thus appears to be a widely distributed, and perhaps universal, aspect of human conceptualizations of time. ${ }^{40}$ If Latin is fairly typical of the world's languages in this respect, what possible cultural significance do its metaphors of time have, then? Its conforming to a pattern of metaphorical meaning common to many languages and cultures hardly seems to lend itself to the characterization of what is distinctive about Roman culture.

In my view, linguistic metaphors become anthropologically revealing when they appear to be reflected in configurations of culture at large —-when they are "made real," that is, in a society's institutions, practices, material objects. Correspondences that Maurizio Bettini has pointed out between Latin's time metaphors and certain socially instituted genealogical representations therefore seem telling. He has argued that the vertical metaphor of time can in fact be detected in 
the form of the aristocratic stemma, where the understanding of temporal relations in terms of "above" and "below" is given concrete realization in the spatial arrangement of imagines of family members of different generations, with members of older generations located "above" and those of younger generations located "below." Thus, he writes, "the 'high' character attributed to earlier time and the 'low' character attributed to later time," "find a precise correspondence and illustration in the structure of the genealogical stemma." ${ }^{41}$ The horizontal metaphor, meanwhile, can be seen to give shape to the pompa funebris, where actors impersonating family members of older generations come physically "before" and younger generations "after" in the processional line escorting the deceased's body. In other words, “Before' is where the founder comes . . . 'Behind' . . f follow the more recent ancestors ... and last of all, farther behind than everyone, comes the latest member of the line to die". ${ }^{42}$

I would add that what likely accounts for the specific axial orientations of these forms of genealogical representation - namely, the verticality of the stemma and the horizontality of the funeral procession—is the "main meaning focus" of each metaphor. ${ }^{43}$ What I mean is that, symbolically speaking, the stemma is "about" the organization of a kinship group as it occurs irrespective of any one individual — and thus its representation of temporal relations in spatial terms of "above" and "below" finds motivation in the more allocentric construal of time provided by the vertical image. The funeral procession is instead about the position of single individual within the generational order-so the horizontal image, which captures a more egocentric view of time, provides a basis for its representation of temporal relations in terms of "before" and "behind." Put differently, in the stemma, the ordering of generations is arranged vertically because in this case the network of family relations (or a portion of it) is meant to be represented without reference to the viewpoint of any person within this network, and the vertical metaphor engenders just such 
a perspective-neutral understanding of temporality. In the funeral procession, the ordering of generations is arranged horizontally because attention is meant to be called to the position of a single family member within this ordering, and the horizontal metaphor captures this sort of perspective-specific view of temporal relations. ${ }^{44}$

Now, in making such a claim I may seem to be privileging abstract conceptual principles over other more concrete physical considerations that may also (or in greater measure) constrain forms of symbolic expression. After all, if the stemma consists of imagines displayed on a wall, is it not natural that the order of generations should be represented in terms of vertical spatial relations? Likewise, given the reality of parading through streets (especially narrow Roman ones), how else could this order be represented if not in terms of horizontal relations? More than anything, basic physics seems to shape the unfolding of these symbolic forms along a particular spatial axis. This largely misses the point, however. Of course, objects arrayed on a vertical surface must be located some "above" and some "below." Of course, bodies traversing a horizontal surface must come some "before" and some "after." Yet this does not explain why, in the first place, Latin speakers should have found a procession to be an effective representation of generational ordering in the perspective-specific context of a funeral, or why they should have considered the stemma most suitable to providing a deictically-neutral view of kinship relations. What makes each of these forms a fitting choice in context is, as I see it, the operation of these distinct metaphors of time and the particular construal of temporal relations that they severally engender. If the choice seems natural and intuitive, it is only because our culture largely shares these metaphors.

At the same time, I may seem to be advocating a strongly Whorfian position on the relationship between language and thought: that is, that the structure of the Latin language, including its metaphorical structure, determines (in the sense of "limits") its speakers' possible ways of 
conceiving and thus also of representing experience. Though such a position would not be entirely indefensible - experimental studies have shown that the grammatical structure of a language can, in certain circumstances, influence thought and even perception- this is not in fact the argument I am making. ${ }^{45}$ My claim, instead, is that the vertical and horizontal metaphors very clearly recognizable in Latin speakers' talk about time operated in Roman society at the level of shared conceptualization —in a word, at the level of culture — and as such provided "ready-made" models of understanding capable of delivering certain schematic images and thus certain meanings through language as well as through other forms of symbolic representation. In other words, in my view, the metaphorically structured conceptualizations that Latin speakers have of time are prior to their encodings in any particular verbal, visual, or behavioral form. If the forms of the patrician stemma and funeral procession make sense to Latin speakers, it is because they are maximally coherent with conceptualizations that also motivate conventional patterns of speech in Latin, not because they depend on these linguistic patterns.

From this perspective, it is interesting to compare Latin's LINEAR metaphors of time with ways of expressing temporal relations in Greek. As examples (55) through (63) reveal, Greek speakers sometimes talk about times of day, seasons, years, or periods of life as "coming" or "approaching" towards a person:

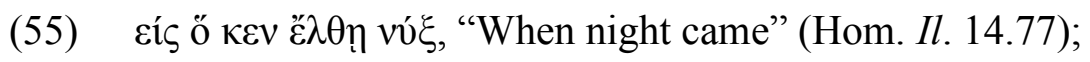

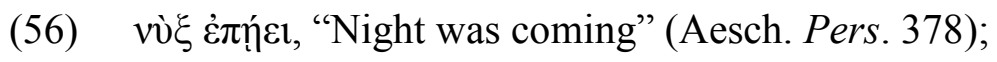

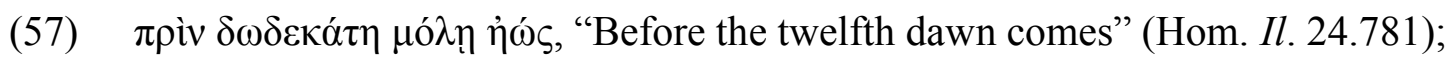

(58) $\mu \dot{\varepsilon} \mu \beta \lambda \omega \kappa \varepsilon \mu \alpha \dot{\lambda} 1 \sigma \tau \alpha \tilde{\eta} \mu \alpha \rho$, "The day has almost passed" (Od. 17.190).

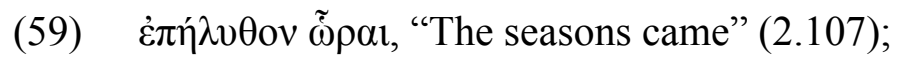

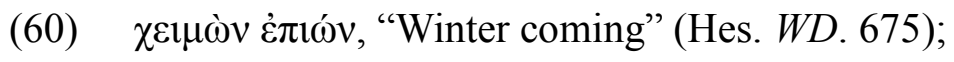




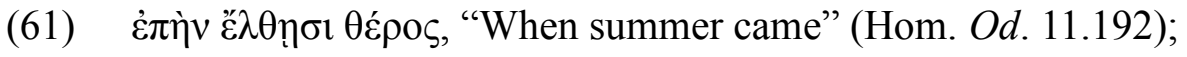

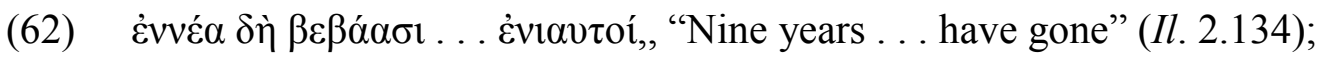

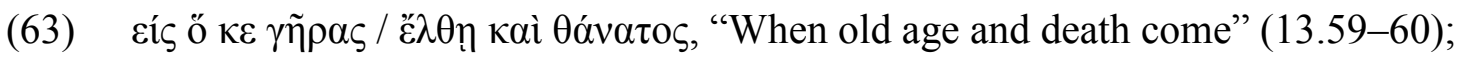

Examples (64) to (68) show that they can also talk about a subject as "arriving at" or "coming to" particular times:

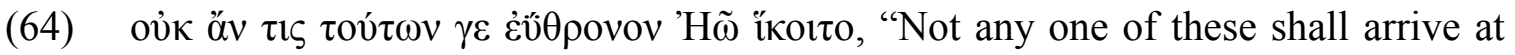
well-throned dawn" (Hom. Od. 17.497);

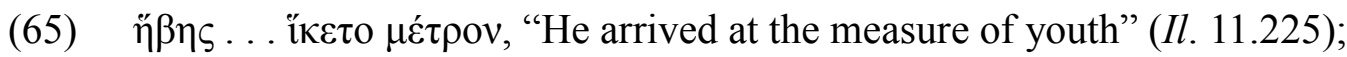

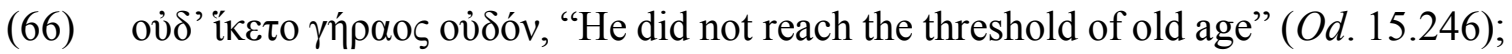

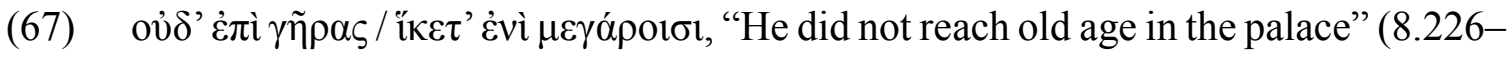
27);

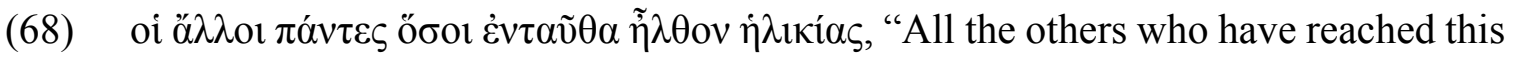
time of life" (Plat. Rep. 329b);

This indicates Greek largely shared Latin's horizontal metaphor in both its "time-moving" and

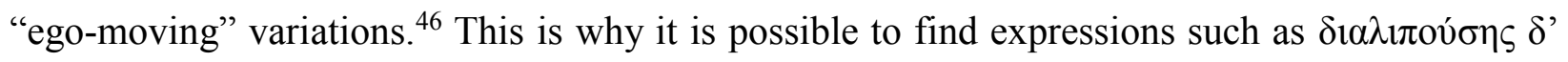

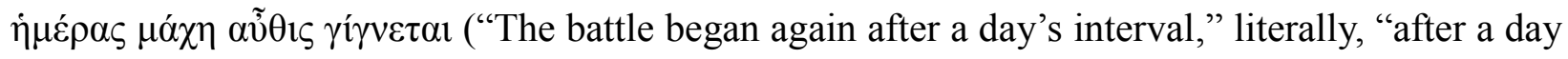

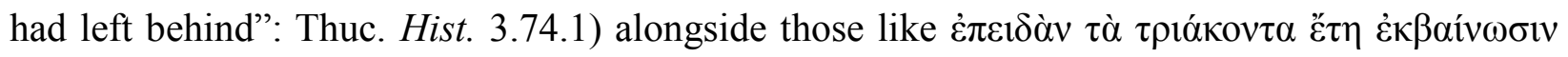
("when they are more than thirty years old," literally, "when they depart from thirty years": Plat. Rep. 537d). Furthermore, as Silvia Luraghi has shown, the Greek preposition $\pi \rho$ ó can signify

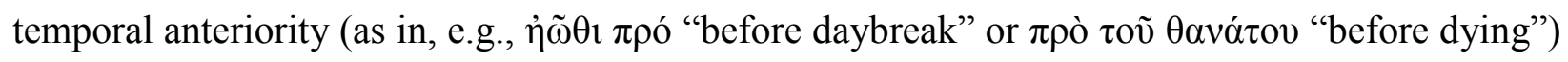
through figurative extension of its literal spatial sense of "in front of," while $\mu \varepsilon \tau \alpha$, literally

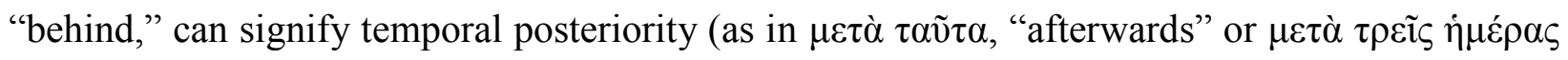


"after three days"), indicating Greek included a time-oriented image as well, even if it appears somewhat more restricted than Latin's. ${ }^{47}$

Traces of a vertical metaphor of time are also detectable in Greek, though words denoting "up" and "down," "above" and "below," or "high" and "low" do not appear to have been employed of temporal relations with the same regularity, or in the same neat conceptual opposition, as in Latin.

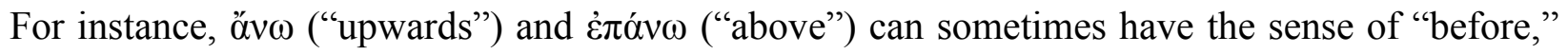
but this usage is limited mainly to the language of Plato and, later, Demosthenes, and Polybius. ${ }^{48}$ Furthermore, a word like ökpos, "high(est)" may be used in certain (mostly poetic) contexts in the

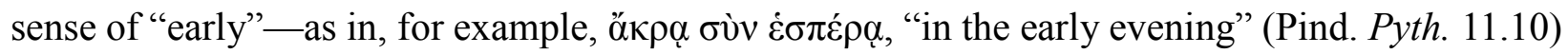

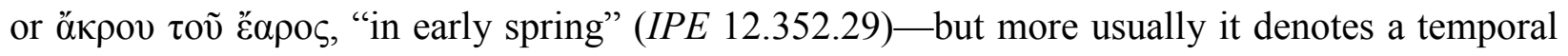

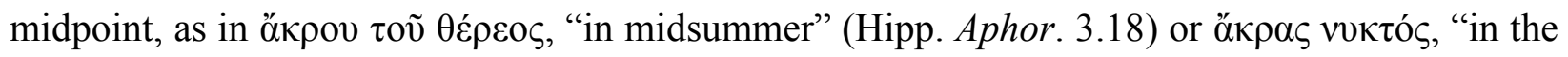

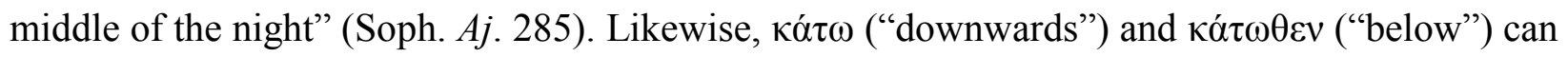

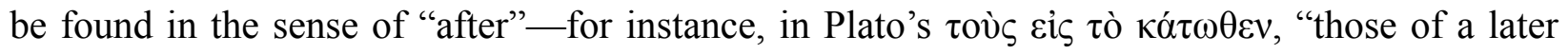
period" (Tim. 18d) - but this usage is infrequent before the Roman era and its increasing appearance in authors like Aelian and Plutarch likely indicates influence from Latin. And

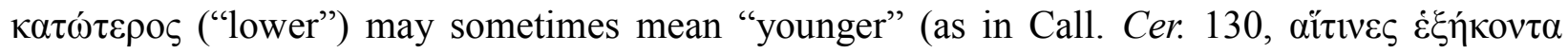

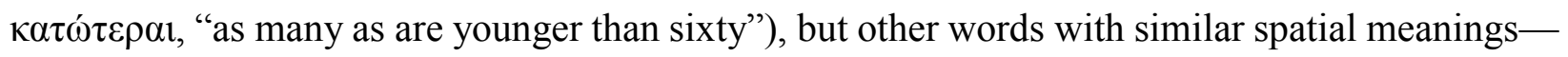

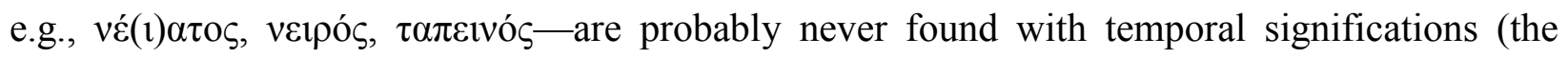

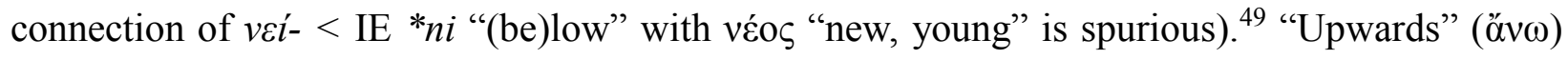

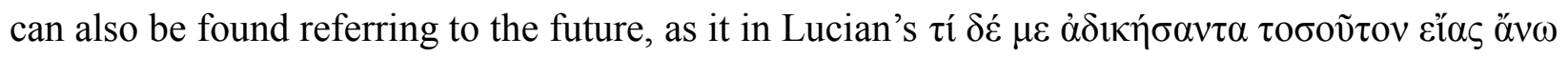

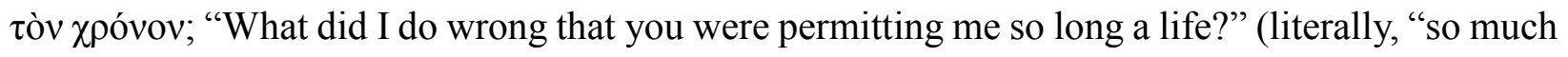
up time") (Cat. 7.6). 
Greek and Latin's LINEAR metaphors of time only partially overlap, then. If Latin speakers made ready use of "up" and "down," "above" and "below," "high" and "low" in conceptualizing temporal relations, the image of a vertical line does not appear to have afforded the Greek imagination the same coherent metaphor for these purposes. The difference seems more than a linguistic curiosity, however. Given Greek speakers' lack of any systematic vertical metaphor of time and thus of any symbolic motivation, as part of their culture, for representing the temporal ordering of generations in these terms, it cannot appear coincidental that Greek society's principal model of family relations - the $\grave{\alpha} \gamma \chi 1 \sigma \tau \varepsilon i ́ \alpha$ —envisioned the group of "close kin" as composed almost exclusively of contemporary "horizontal" ties. ${ }^{50}$ Or that family genealogies, when they were kept, typically took the form of lists or narratives similar to the catalogues of Homeric epic, preserved orally or in writing, but were never represented in any material, artifactual form similar to the Roman stemma. ${ }^{51}$ Athenian notions of autochthony, according to which what comes "before" is "below" and what comes "after" is "above," in fact appear to presuppose a model of temporal relations that fully inverts the stemma's vertical scale. ${ }^{52}$ This suggests that Greek's conceptual system, without any consistent spatialization of time in terms of "above" and "below," did not commit its speakers to any particular organization of temporality along the vertical axis.

To be clear. I am not suggesting that the stemma would have been incomprehensible to Greek speakers. Even if a vertical metaphor of time was marginal in their conceptual system, its availability nevertheless implies Greek speakers could easily have intuited the stemma's meaning, even if its form would not have appeared particularly salient. On the other hand, it is hard to imagine what sense Roman representations of kinship would have made to speakers of Aymara, who conceptualize time as a static physical landscape where the future is behind the speaker and the past is in front of the speaker — saying, for instance, qhipa mara, literally "back year," for "next 
year" and nayra mara, literally, "front year," for "last year" and gesturing accordingly. ${ }^{53}$ Or for that matter to speakers of the Australian language Kuuk Thaayorre, which expresses spatial relations in terms of absolute cardinal directionality (so, to say that something is in front of you, you say it is to the north, if facing north; to the east, if facing east, and so on). Though spatial words are not regularly used metaphorically of time in this language, its speakers nevertheless appear to conceptualize temporal relations according to this system. When asked to place pictures depicting some sequence of actions in temporal order, for example, they consistently arrange earlier images towards the east and later images towards the west (regardless of the direction they are facing), obviously on the model of the sun's path through the sky during the course of a day. ${ }^{54}$

Latin's vertical and horizontal images of time-each with its more allocentric or more egocentric construal of temporal relations - in fact appear to automatically structure how Latin speakers go about representing temporal relations to themselves in their symbolic expression. Consider the farmers' almanac stone from Rome (1st c. CE) or for that matter the fragmentary wall-calendar from Antium (84-55 BCE), reproduced in Figures 5 and 6.<FIGURE 5: Farmers' almanac stone. Rome, 1st c. CE $=$ ILS 8745. $><$ FIGURE 6: Fasti Antiates Maiores. Antium, 84-55 BCE.> Both represent the order of the months of the year along the horizontal axis and the order of days within each month (the most religiously important ones, at any rate) along the vertical axis. The selection of the horizontal axis for representing the division of the year into months and of the vertical axis for the division of each month into days is very likely conditioned again by the "main meaning focus" of each metaphor. The horizontal axis is preferred for the months of the year because the position of each month in the annual sequence is a matter of more subject-specific relations: February follows January, March follows February, and so forth. The months are (more) "egocentric" in the sense that they are specifically named, each constituting a distinct subjectivity 
within a determined ordering. Indeed, in Roman culture the months are very often anthropomorphized and thus have a definite "facing": 55 this is why Janus, who ends the old year and begins the new year, is represented as looking in two directions, both forward and backward along the horizontal time line. ${ }^{56}$ The vertical axis is instead preferred for the days of the months because the ordering of the days within the month is more allocentric, in the sense that, particularly in the Fasti, the same pattern repeats itself without significant differentiation for each of the months (the relations between the days of the months being a feature of the system as a whole) and that, with the well-known exceptions of the Kalends, Nones, and Ides, they do not have an articulated nomenclature. The days of the month have a specific numerical ordering (e.g., ante diem tertium, quartum, quintum Nonas Ianuarias), but are subject-neutral - they do not "face" one another.

Or take the marble relief from Amiternum shown in Figure 7.<FIGURE 7: Marble relief depicting a funerary procession. Amiternum, c. 50 BCE. Now in the Museo Nazionale d'Abruzzo, L'Aquila.> It depicts a funeral procession: at right are the musicians who lead the parade, farther to the left is the deceased's bier, and finally at the far left his bereaved descendants. Time thus unfolds along a horizontal axis from right to left, "right" being before and "left" after (in projecting the image to two-dimensional space, Roman culture appears largely neutral as to the lateral directionality of the time line). At the same time, the relief's vertical registers appear to define an additional temporal scale, at least in part. Though the scenes of mourning on the left presumably take place simultaneously to the procession and so demonstrate no temporal distinction between registers, the parade of musicians on the right extends over two registers clearly differentiated temporally. The horn-blowers and trumpeter at top represent those who come first in line, while the pipers at bottom are following. Time thus also runs vertically with before "above" and after "below." Again, however, even taking into account the particular (not to say peculiar) constraints 
placed on representations of time and space in ancient forms of art, ${ }^{57}$ the horizontal and vertical axes appear to differ in their meaning focus. As with the lived pompa funebris, selection of the horizontal axis to represent the deceased's position within the order of generations is likely motivated by the more subject-specific character of the horizontal metaphor time; the vertical axis is chosen to represent temporal relations detached from this perspective because of vertical time's more subject-neutral framing. ${ }^{58}$

\section{CONCLUSIONS.}

In this paper, I have argued that certain patterns of figurative meaning in Latin's expressions of time are also recognizable in Roman society's symbolic activities more broadly. Specifically, I argued that Latin speakers' conceptualization of time is structured metaphorically (in part) by image schemas of linear spatial relations, and suggested that the understanding of temporal relations delivered by these metaphors differs in at least one respect: namely, that the vertical image of time construes the ordering of times allocentrically (without reference to any subject), whereas through the horizontal image construes this ordering egocentrically (always relative to a viewpoint). I then indicated a number of contexts in which each metaphor's main meaning focus appears to motivate the specific axial arrangements of visual representations.

These have only been hints. Nevertheless, as patterns of meaning whose organizing effects are detectable widely over Roman society's symbolic expression, the interest of these metaphors seems to go beyond claims as to their universality. In structuring a significant portion of Latin speakers' conventional talk about time, as well as providing a regular model for the topographical distribution of temporally related events in visual space, they appear to constitute an important “theme" of Roman cultural representation. Indeed, if Latin speakers' everyday talk, ritualized 
behaviors, and interaction with objects in even seemingly unrelated areas of life-kinship practices, calendar making, the visual arts-all embodied the same metaphorical structuring of time in linear spatial terms, this would have contributed to a perception of these activities as coming together under a cohesive signifying order. Topography, too, would have corroborated this perception, as the urban environment itself seems to have afforded a context of lived experienced perfectly recapitulating this metaphorical structure. Climbing the Palatine Hill to where Romulus' hut could be seen, or the Capitoline Hill to where the arx and other monuments of the city's earliest history stood, a Latin speaker would have appreciated 'BEFORE IS ABOVE' as a feature of the landscape. Similarly, walking from, say, the temple of Mars Ultor through the porticoes of the Forum of Augustus, where statues of the Julian family and of Rome's summi viri were displayed chronologically earliest to last, a Latin speaker would have recognized 'AFTER IS IN FRONT OF $(E G O)^{\prime}$ ' as something literally true of the world.

The sorts of conclusions that can be drawn about Latin's time metaphors specifically imply that attending to the image-schematic and metaphorical structuring of concepts generally can offer benefits to classical studies. First, it offers teachers of the classical languages a framework for explaining and thus making more readily comprehensible to students the meanings of idioms in Latin and Greek. When seemingly semantically opaque idiomatic expressions can be contextualized within pervasive metaphorical themes, the meanings of those idioms should become reasonable and inferable and therefore easier to learn: As Susan Irujo argues, "Teaching students strategies for dealing with figurative language will help them to take advantage of the semantic transparency of some idioms. If they can figure out the meaning of an idiom by themselves, they will have a link from the idiomatic meaning to the literal words, which will help them learn the idiom." ${ }^{59}$ By giving students linguistic and cultural knowledge that helps them to 
reason metaphorically "in the native's own terms" (that is, to think the way a Roman might have thought), this approach may actually enable students to make the kind of contextually-dependent predictions of meaning that are necessary for understanding not only the grammatical and lexical cohesion of texts but also their coherence with (and within) the cultural system. ${ }^{60}$

Second, it affords the possibility of taking a more "emic" perspective in our analyses of the Latin language and of Roman literature. An emic perspective, as we know, privileges "native" ways of knowing and of representing the world, rather than concepts belonging to the observer's own intellectual framework. ${ }^{61}$ By illustrating how even demonstrably human-universal patterns of conceptualization can come to be articulated in idiosyncratic ways across the creative expression of a particular "languaculture" (to use Michael Agar's handy portmanteau) ${ }^{62}$ a metaphor-based approach promises to reveal the sorts of symbolic "themes" or "macrosignifieds" that go toward making up a society's distinctive repertoire of meanings: in a word, its culture. Certainly, anthropology has long been interested in the thematicity of culture, from Ruth Benedict's definition of culture as "personality writ large," to Clyde Kluckhohn's concept of "configurations," to Claude Lévi-Strauss' "cultural axioms," and Clifford Geertz's "cultural templates." Yet an awareness that metaphor is probably the form of symbolic representation most directly revealing of this aspect of culture is only now congealing as part of the "cognitive revolution" taking place in the social sciences and humanities. Especially when combined with a culturally-comparative perspective, a metaphor-based approach can highlight how the images through which Latin speakers' "capture" their concepts may be based on experiences shared by presumably all human beings, their privileging of certain experiences in metaphorical conceptualization constitutes a distinctive feature of their signifying order. 
More generally, it suggests the possibility of helping to bridge the gap between the interpretation of texts on the one hand and works of art and architecture on the other. In treating metaphor as a matter of conceptualization, it takes as granted that the same figurative relationships shaping forms of linguistic expression will be manifest also in the alimentary, vestimentary, gestural, and kinesic codes underlying social behavior, as well as in the aesthetic codes that underpin material culture. Of course, by "same" I do not mean that the visual code should be treated as merely a calque on the linguistic. It is possible to take Hölscher's metaphor too literally. The point is not to seek some kind of one-to-one correspondence between certain rhetorical figures of speech and visual configurations, or between certain strategies of literary description (even in terms of favored syntactic constructions) and motifs of artistic composition. In a cognitivist perspective, all representational modalities are grounded in the same conceptual structures (including metaphorical ones) and guided by the same cognitive processes of meaning making. The point, then, is to discover how language and art, as distinct forms of representation each with its own standards of signification, convey the repertoire of shared meanings (including metaphorical meanings) that constitute a society's signifying order: in a word, its culture. A metaphor-based approach therefore lends itself very well to bringing together a cognitive archaeology and a cognitive linguistics under a unified method capable of delineating a distinctively Roman way of having the world. ${ }^{64}$

${ }^{1}$ J. Whitley, The Archaeology of Ancient Greece (Cambridge 2001). Cf. S. Marchand, Down from Olympus (Princeton 1996) and J. Tanner, The Invention of Art History in Ancient Greece (Cambridge 1996) 15-21.

2 J. Elsner, ed., Art and Text in Roman Culture (Cambridge 1996) 1. 
${ }^{3}$ Cases where a specific correspondence can be established between a literary work and a work of art have been amply discussed by, e.g.: K. Schefold, Myth and Legend in Early Greek Art (London 1966); C. Johanson, "A Walk with the Dead," in B. Rawson, ed., A Companion to Families in the Greek and Roman Worlds (Oxford 2011) 408-430; S. Lowenstam, "The Uses of Vase-Depictions in Homeric Studies," TAPA 122 (1992) 165-98 and "Talking Vases: The Relationship between the Homeric Poems and Archaic Representations of Epic Myth," TAPA 127 (1997) 21-76; S. Goldhill S. and R. Osborne, eds., Art and Text in Ancient Greek Culture (Cambridge 1993); H. Shapiro, Myth Into Art (London 1994); Elsner, J., ed., Art and Text in Roman Culture (Cambridge 1996); A. Snodgrass, Homer and the Artists (Cambridge 1998); M. Stansbury-O'Donnell, Pictorial Narrative in Ancient Greek Art (Cambridge 1999); N. Rutter, and B. Sparkes, eds., Word and Image in Ancient Greece (Edinburgh 2000); J. P. Small, The Parallel Worlds of Classical Art and Text (Cambridge 2003); and now L. Giuliani, Image and Myth (Chicago 2013).

${ }^{4}$ On ekphrasis, see esp. F. Zeitlin, "The Artful Eye," in S. Goldhill and R. Osborne, eds., Art and Text in Ancient Greek Culture (Cambridge 1993) 138-96; R. Webb, Ekphrasis, Imagination, and Persuasion in Ancient Rhetorical Theory and Practice (Farnham 2009); and I. De Jong, ed., Space in Ancient Greek Literature (Leiden 2012).

${ }^{5}$ Cf., e.g., D. Steiner, Images in Mind (Princeton 2001).

${ }^{6}$ C. Berard, Essais sèmiotiques (Lausanne 1983).

${ }^{7}$ T. Hölscher, The Language of Images in Roman Art (Cambridge 2004).

${ }^{8}$ The perspective of an anthropologically-oriented cognitive semiotics has been developed especially by P. A. Brandt, Spaces, Domains, and Meaning: Essays in Cognitive Semiotics (Frankfurt 2004); G. Palmer, Toward A Theory of Cultural Linguistics (Austin 1996); B. Shore, 
Culture in Mind (Oxford 1996); and M. Danesi and P. Perron, Analyzing Culture (Bloomington 1999).

${ }^{9}$ G. Lakoff and M. Johnson, Metaphors We Live By (Chicago 1980); G. Lakoff, Women, Fire, and Dangerous Things: What Categories Reveal about the Mind (Chicago 1987); M. Johnson, "ImageSchematic Bases of Meaning," Semiotic Inquiry 9 (1989) 109-18; R. Langacker, Grammar and Conceptualization (Berlin 1999); L. Barsalou, "Perceptual Symbol Systems," Behavior and Brain Sciences 22 (1999) 577-660.

${ }^{10}$ Cf. E. Rosch, "Natural Categories," Cognitive Psychology 4 (1973) 328-50; C. Fillmore, "Frame Semantics," in P. Kiparsky, ed., Linguistics in the Morning Calm (Seoul 1982) 111-37; Lakoff (above, n. 6); Johnson (above, n. 6); J. Taylor, Linguistic Categorization: Prototypes in Linguistic Theory (Oxford 1989); S. Atran, Cognitive Foundations of Natural History (Cambridge 1993).

${ }^{11}$ Cf. esp. L. Barsalou, “Ad hoc categories,” Memory \& Cognition 11 (1983) 211-27 and "Ideals, central tendency, and frequency of instantiation as determinants of graded structure in categories," Journal of Experimental Psychological 11 (1985) 629-54.

${ }^{12}$ F. Vallee-Tourangeau, S. Anthony and N. Austin, "Strategies for Generating Multiple Instances of Common and Ad Hoc Categories," Memory 6 (1998): 555-92.

${ }^{13}$ M. Johnson, The Body in Mind (Chicago 1987) xiv.

${ }^{14}$ See esp. R. Gibbs and H. Colston, “The Cognitive Psychological Reality of Image Schemas and Their Transformations," Cognitive Linguistics 6 (1995) 347-78; cf., e.g., T. Ziemke et al., eds., Body, Language, and Mind: Sociocultural Situatedness (Berlin 2008).

${ }^{16}$ See esp. Lakoff and Johnson (above, n. 6); Lakoff (above, n. 6); and Johnson (above, n. 6). 
${ }^{17}$ Cognitive linguists take image schemas to deliver the "structured" or "motivated polysemy" of words: see, e.g., H. Cuyckens and B. Zawada, eds., Polysemy in Cognitive Linguistics (Amsterdam 2001).

${ }^{18}$ W. M. Short, "Latin De: A View From Cognitive Semantics," Classical Antiquity 32 (2013) $378-405$.

${ }^{19}$ M. Bettini, Anthropology and Roman Culture: Kinship, Time, and Images of the Soul (Baltimore 1991.

${ }^{20}$ Because the ABOVE/BELOW schema imposes a relative rather than absolute scale of values on time (i.e., there is no fixed temporal reference point according to which times are reckoned: see below), it is normal that we find the comparative forms of superus and inferus used in temporal referencing. The usage of Cic. Arat. fr. 310 (vv. 72-73), atque etiam supero navi pelagoque vacato

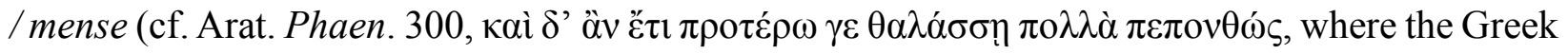
shows a comparative) is perhaps due to metrical considerations. Superlative supremus in the temporal sense of "last, final" (cf. suprema, "last part of the day" and the idiom diem supremum obire ("go to meet the final (literally, 'highest') day")) — where according to the metaphor the meaning should be "earliest"-is probably by analogy to extremus. Cf. O. Spevak, The Noun Phrase in Classical Latin Prose (Leiden 2014) 172-73; P. Poccetti, "Ultimus et proximus entre fonctions anaphoriques et fonctions déictiques du latin et des langues sabelliques aux développements romans," in M. Fruyt and O. Spevak, eds., La quantification en latin (Paris 2011) $273-90$.

${ }^{21}$ Here, and below, my selection of examples is intended to illustrate - to the extent possible - the temporal range of the metaphorical mapping in question, as well as its distribution across different authors, genres, and forms of linguistic encoding. The lists are meant to be representative samples, 
rather than exhaustive catalogues; they are normally organized primarily by linguistic form and secondarily in chronological order. Even if it is not always possible to find examples of each of the mappings at every period of the language, most are widely represented in Latin semantic system over time, giving the system a claim to diachronic validity.

${ }^{22}$ More conventionally, minores natu expresses the notion of "(those) younger," by means of a metaphor from physical magnitude: see n. 23 .

${ }^{23}$ Bettini (above, n. 19) 167-68 explains the meaning of the genealogical terms maiores ( "ancestors"), aequales ("coevals"), and minores ("descendants") according to the same metaphor of verticality (in this case, the vertical axis being divided into three temporal segments). These are perhaps better understood in terms of a metaphor of physical magnitude, however-older being "larger" and younger being "smaller"- that is strongly motivated by experience (for much of our lives, those older than us are typically also bigger). Indeed, aequalis probably should be construed as an image of uniformity of size or appearance (cf. Verg. Cir. 435, florentes aequali corpore nymphae) rather than one of "levelness" on a vertical scale. We should also note that minores does not normally denote one's descendants, but one's younger siblings (minores natu); usage of the word in this sense is poetic and limited to Verg. Aen. 1.532, Hor. Ep. 2.1.106, and Ov. Tr. 4.1055 and a very few other examples, where contrast with maiores is specially highlighted.

${ }^{24}$ In Figure 2, PAST and FUTURE (rather than BEFORE and AFTER as in Figure 1) highlight that the position of ego corresponds to a "now" that divides the time line absolutely.

${ }^{25}$ It is probably possible to explain expressions like a pueritia (e.g., Cic. Sull. 70) or recens ab illorum aetate fuit (ND. 3.11) via this image as well. In such cases, times ("boyhood," "their period") are construed as regions or extents of the time line and being "away from" a certain timeregion - that is, with this region canonically behind one - means for it to be in one's past. 
${ }^{26}$ I have explained the temporal meanings of the preposition de in terms of an image schema entirely coherent with the horizontal image of the time line: see Short (above, n. 18) 395. The sense of "after" (e.g., diem de die) emerges when two times are understood in relation to one another in the perspective of the subject-moving metaphor: one event-location that is perceived to be "away from" another (that is, at a point further along the path of time) will be understood as occurring "after" it. That of "during" (e.g., de vigilia, de nocte) emerges when two times are interpreted in the perspective of the time-moving image as marking the start- and end-points of a single durative circumstance, and conceptual focus is on the intervening spatial expanse, understood as the time over which something occurs. Similarly, a preposition like secundum will have the temporal meaning it does (cf. Plaut. Stich. 3.1.45, ite hac secundum vos me) because a time that is "following behind" another is, according to the same image, the one occurring "immediately after."

${ }^{27}$ Lakoff and Johnson (above, n. 6); Z. Kövecses, Metaphor: A Practical Introduction (Oxford 2002) and Metaphor in Culture: Universality and Variation (Cambridge 2005).

${ }^{28}$ This is why the metaphor occurs when the "worth" of some time-consuming activity-for example, service to the emperor (Tac. Ann. 12.65); the pursuit of fame (Stat. Silv. 5.1.63); recounting Augustus' achievements (Vell. Pat. Hist. Rom. 2.89)—is at issue. The commoditization of time was not nearly as developed in Latin speakers' cultural system as it has become in English speakers' since the Industrial Revolution, however: Lakoff and Johnson (above, n. 6) 7-9.

${ }^{29}$ The metaphor may also relate to the image of the Parcae who "unroll" time like a scroll: cf. M. Putnam, Virgil's Epic Designs: Ekphrasis in the Aeneid (New Haven 1998) 134-38.

${ }^{30}$ E.g., Liv. AUC. 3.10.8, ut idem in singulos annos orbis volveretur, "that the same "circle of events' may revolve every year"; 3.36.3, insigne regium in orbem per omnes iret, "the regal badge passes to all 'in a circle'." 


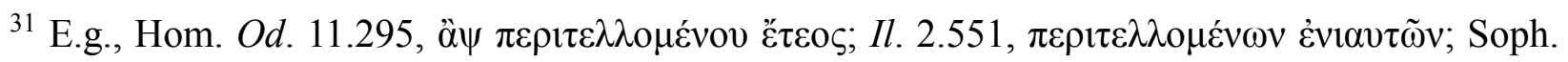

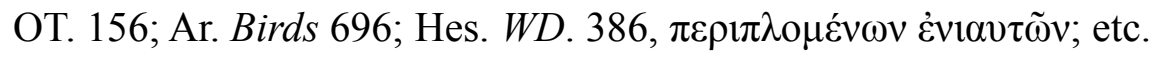

32 Lakoff and Johnson (above, n. 6) 14-17; Lakoff (above, n. 6) 275; T. Krzeszowski, “The Axiological Parameter in Preconceptual Image Schemata," in R. Geiger and B. Rudzka-Ostyn, eds., Conceptualizations and Mental Processing in Language (Berlin 1993) 321.

33 ABOVE/BELOW and FRONT/BACK in fact appear to be concepts of fundamentally different character. "Above" and "below" are perceptual primitives whose understanding emerges developmentally before that of "in front of" and "in back of," which involve a cluster of subjective and intersubjective features. Infants as young as three months can categorize objects as above or below a line, while front and back are not acquired before perhaps nine months: P. Quinn and P. Schyns, "What Goes Up May Come Down: Perceptual Process and Knowledge Access in the Organization of Complex Visual Patterns by Young Infants," Cognitive Science 27 (2003) 923-35; T. Regier, The Human Semantic Potential: Spatial Language and Constrained Connectionism (Cambridge, Mass. 1996); S. Levine and S. Carey, "Up Front: The Acquisition of a Concept and a Word," Journal of Child Language 9 (1982) 645-57.

${ }^{34}$ Cf. J. McTaggart, “The Unreality of Time,” Mind 17 (1908) 457-74; N. Measor and M. Shorter, “Subjective and Objective Time," Aristotelian Society Supplementary Volume 60 (1986) 207-234; etc.

35 The concept of "folk model" has been developed particularly by Holland and Quinn 1987; R. D’Andrade, "Some Propositions about Relations Between Culture and Cognition,” in J. Stigler et al., eds., Cultural Psychology: Essays on Comparative Human Development (Cambridge 1990) 65-129; and R. D’Andrade and C. Strauss, eds., Human Motives and Cultural Models (Cambridge 1992). 
${ }^{36}$ See esp. M. Brdar et al., eds., Space and Time in Language (Frankfurt 2011); D. Casasanto, "Space for Thinking," in V. Evans and P. Chilton, eds., Language, Cognition, and Space (London 2010) 453-78; K. Moore, "Space to Time Mappings and Temporal Concepts," Cognitive Linguistics 17 (2006) 199-244; G. Radden, “The Metaphor TIME AS SPACE across Languages," in E. Górska and G. Radden, eds., Metonymy-Metaphor Collage (Warsaw 2006) 99-120; L. Boroditsky, "Metaphoric Structuring: Understanding Time through Spatial Metaphors," Cognition 75 (2000) 1-28; H. Alverson, Semantics and Experience: Universal Metaphors of Time in English, Mandarin, Hindi, and Sesotho (Baltimore 1994).

${ }^{37}$ English speakers will talk of times "coming up," but this is because in English the canonical location of ego is "up" rather than "down" and also because what is visible is "up." It is also possible to say that something "goes down" in history, but this is usually said of infamous deeds and probably relates to the metaphor 'BAD IS DOWN'.

${ }^{38}$ E. Sweetser and B. Dancygier, Figurative Language (Cambridge 2014) 172. English speakers also speak of the "High Middle Ages" and the "High Renaissance" but these designations have more to do with cultural achievements than with the relative temporality of the named period: that is, the "High Middle Ages" (c. the 11th to 13th centuries) are so called because they were marked by particularly noteworthy social, political, and artistic developments.

${ }^{39}$ L. Boroditsky et al., "Do English and Mandarin Speakers Think about Time Differently?" Cognition 118 (2011) 123-29.

${ }^{40}$ Cf., e.g., H. Clark, "Space, Time, Semantics and the Child," in T. Moore, ed., Cognitive Development and the Acquisition of Language (New York 1973) 27-63; E. Traugott, "On the Expression of Spatio-Temporal Relations in Language," in J. Greenberg et al., eds., Universals of Human Language (Stanford 1978) 369-400; M. Haspelmath, From Space to Time: Temporal 
Adverbials in the World's Languages (Munich 1997); D. Gentner, "Spatial Metaphors in Temporal Reasoning," in M. Gattis, ed., Spatial Schemas and Abstract Thought (Cambridge 2001) 203-222; V. Evans, The Structure of Time (Amsterdam 2004); G. Fauconnier and M. Turner, "Rethinking Metaphor," in R. Gibbs, ed., The Cambridge Handbook of Metaphor and Thought (Cambridge 2008) 55; W. Klein, "How Time is Encoded," in W. Klein and P. Li, eds., The Expression of Time (Berlin 2010) 9-82. But see C. Sinha et al.,"When Time is Not Space," Language and Cognition 3 (2011) 137-69.

${ }^{41}$ Bettini (above, n. 19) 170.

${ }^{42}$ Bettini (above, n. 19) 179. For in-depth discussion of the sources related to the aristocratic stemma (mainly Sen. Ben. 3.28.2 and Plin. NH. 35.6) and pompa funebris (esp. Polyb. Hist. 6.53), the reader is referred to Bettini (above, n. 19) 169-81.

${ }^{43}$ On the concept of a metaphor's “main meaning focus," see Z. Kövecses, Metaphor and Emotion: Language, Culture, and Body in Human Feeling (Cambridge 2003) 82-84.

${ }^{44}$ Probably only the most politically distinguished members of the family were represented in the stemma and pompa funebris: see H. Flower, Ancestor Masks and Aristocratic Power in Roman Culture (Oxford 1996). One of Classical World's anonymous referees points out, as well, that under the principate the pompa funebris was significantly restructured so that the emperor, though most recent, came first in line (as also in the laudatio funebris). This suggests that that although the horizontal metaphor of time provides a kind of organizing image motivating the spatial unfolding of this practice, other considerations (including social ones) might interfere with and even invert the schema provided by the metaphor: cf. W. Kierdorf, Laudatio funebris: Interpretationen und Untersuchungen zur Entwicklung der römischen Leichenrede (Meisenheim 
am Glan 1980) and E. Flaig, Ritualiserte Politik: Zeichen, Gesten und Herrschaft im Alten Rom (Göttingen 2004).

${ }^{45}$ See esp. J. Lucy, Grammatical Categories and Cognition: A Case Study of the Linguistic Relativity Hypothesis (Cambridge 1992).

${ }^{46}$ Sanskrit agra- (both "front" and "before") along with paśća- ("behind" and "after") indicate the metaphor may be inherited. Horizontal metaphors of time in Greek have been studied esp. by J. Palm, "Lag die Zukunft der Griechen hinter ihnen?" Annales Academiae Regiae Scientiarum

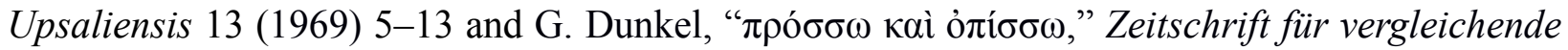
Sprachforschung 96 (1982) 66-87. From very different perspectives, see also I. De Jong and R. Nünlist eds., Time in Ancient Greek Literature (Leiden 2007) and A. Purves, Space and Time in Ancient Greek Narrative (Cambridge 2010).

${ }^{47}$ S. Luraghi, On the Meaning of Prepositions and Cases (Amsterdam 2003) 155-65 and 245-55.

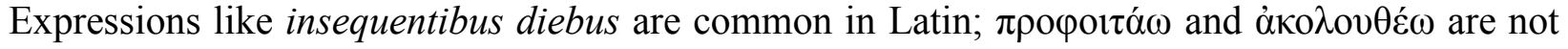
conventionally used in temporal senses in Greek, however.

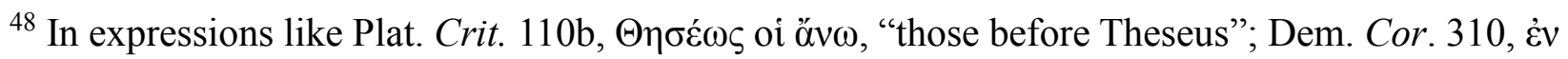

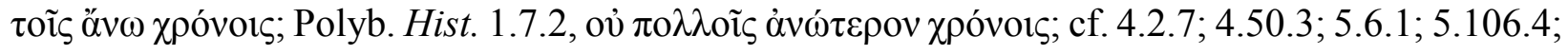
21.11.2; etc. During the Roman period, the usage becomes increasingly frequent, e.g., in the works of Arrian, Aelius Aristides, and Aelian, probably under the influence of Latin.

${ }^{49}$ Meanwhile, Greek speakers seem to privilege metaphors of quantity or size when speaking about

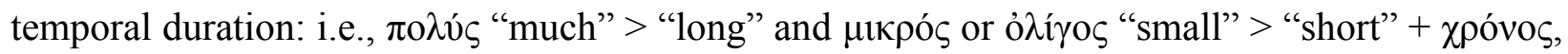
images that are quite circumscribed in Latin (perhaps only in multa de nocte, ad multam noctem, and the like; not inconsistently with a spatial interpretation, however: cf. Symmach. Ep. 2.51, haud multum processit horae). The metaphor is particularly prevalent in modern Greek: D. Casasanto, 
"Who's Afraid of the Big Bad Whorf? Cross-Linguistic Differences in Temporal Language and Thought," Language Learning 58 (2008) 70-72.

${ }^{50}$ L. Foxhall, "Monumental Ambitions: The Significance of Posterity in Greece," in N. Spencer, ed., Time, Tradition, and Society in Greek Archaeology (London 1995) 134 and "Family Time: Temporality, Gender, and Materiality in Ancient Greece," in J. Marincola et al., eds., Greek Notions of the Past in the Archaic and Classical Eras (Edinburgh 2012) 187-188.

${ }^{51}$ C. Calame, "Spartan Genealogies: The Mythological Representation of a Spatial Organisation," in J. Bremmer, ed., Interpretations of Greek Mythology (London 1987) 153-86; cf. R. Thomas, Oral Tradition and Written Record in Classical Athens (Cambridge 1992) 155-95.

${ }^{52}$ See esp. N. Loraux, The Invention of Athens (Cambridge, Mass. 1986) 18-19 and 39-40; and The Children of Athena (Princeton 1993) 3-22 and 37-71; V. Rosivach, "Autochthony and the Athenians," Classical Quarterly n.s. 37 (1987) 294-305.

${ }^{53}$ R. Núñez and E. Sweetser, "With the Future Behind Them," Cognitive Science 30 (2006) 40150. As A. Ort (Catechizing Culture [New York 2004] 192) has argued, for Aymaraes it is the physical location of a family's house, and the concentrical arrangement of family members inside it in, with the most senior members at the focal point, that best represents "a mnemonic of genealogical continuity".

${ }^{54}$ L. Boroditsky and A. Gaby, "Remembrances of Times East: Absolute Spatial Representations of Time in an Australian Aboriginal Community," Psychological Science 21 (2010) 1635-39.

${ }^{55}$ Cf., e.g., Hor. Ep. 11.5-6, hic tertius December / ex quo destiti / Inachia fuere, silvis honorem decutit; Mart. Ep. 7.37.6, 95.1, etc. In Roman art, the months are normally personified as single figures, "depicted in full activity and never as a symbol" (D. Levi, "The Allegories of the Months in Classical Art," Art Bulletin 23 [1941] 288). 
${ }^{56}$ Cf. B. R. Burchett, Janus in Roman Life and Cult: A Study in Roman Religions (Menasha, Wisc. 1912).

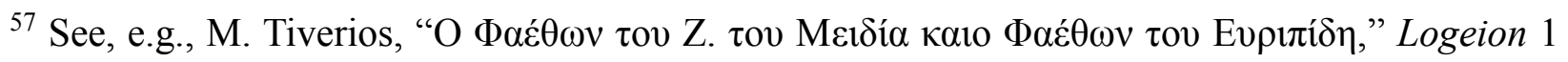
(2011) 94-97.

58 The bier's "bridging" of the vertical registers is interesting in this respect. As both J. Bodel ("Death on Display: Looking at Roman Funerals," in B. Bergmann and C. Kondoleon, eds., The Art of Ancient Spectacle [New Haven 1999] 259-81) and K. Johanson ("A Walk with the Dead," in B. Rawson, ed., A Companion to Families in the Greek and Roman Worlds [Oxford 2011] 408430) have emphasized, beliefs about the deceased's "liminal" position between the living and the dead probably accounts for the bier's sequentially, if not spatially, symmetrical placement (a nearly equal number of human figures precedes as follows it). Together with aesthetic conventions that establish a correspondence between a visual element's relative size and its importance, this may explain why the bier so blatantly violates the vertical division of space: in this way, the deceased's “mediating" function plays out along both temporal axes.

${ }^{59}$ S. Irujo, “A Piece of Cake: Learning and Teaching Idioms,” ELT Journal 40 (1993) 217.

${ }^{60}$ Cf. M. Halliday and R. Hasan, Language, Context, and Text: Aspects of Language in a SocialSemiotic Perspective (Oxford 1985).

${ }^{61}$ See esp. C. Geertz, The Interpretation of Cultures (New York 1973).

62 Whereas "linguaculture" refers to "a domain of experience that fuses and intermingles the vocabulary, many semantic aspects of grammar, and the verbal aspect of culture" (P. Friedrich, “Language, Ideology, and Political Economy," American Anthropologist 91 [1989] 306), suggesting that there are aspects of culture not related to language and aspects of language not related to culture, "languaculture" is meant to capture the inextricability of these categories: "The 
langua in languaculture is about discourse, not just about words and sentences. And the culture in languaculture is about meanings that include, but go well beyond, what the dictionary and the grammar offer" (M. Agar, Language Shock [New York 1994] 96).

${ }^{64}$ Cf. C. Renfrew and E. Zubrow, eds., The Ancient Mind: Elements of Cognitive Archaeology (Cambridge 1994). 